

\section{Article Artículo Paper Participació i coneixements 4 dels "usuaris" i les persones a qui s'adrecen les polítiques}

\section{Slimane Touhami ${ }^{1}$}

\section{Resum}

Des del 2002, a França està regulada la participació de les persones afectades per les activitats de l'àmbit sociosanitari i social per a la valoració del funcionament de les institucions, activitats i programes d'aquests àmbits i per a l'elaboració de propostes. Des d'aleshores ençà, ha estat motiu de reflexió tant per definir-la, fonamentar-la i promoure-la i adaptar el seu desenvolupament als diferents àmbits i a les característiques dels diferents agents que poden estar-hi implicats. A l'article s'identifiquen obstacles que dificulten la participació en el context institucional en relació a les persones afectades, els equips professionals i les institucions mateixes, i para una especial atenció a la manera com la qüestió de la jerarquia i el "poder" pot interferir en el desenvolupament de les propostes de participació, fins i tot quan el que suposadament es pretén és fomentar l'autonomia de les persones amb qui es treballa. Finalment, es fa referència a experiències innovadores $i$, en concret, les que posen en valor el "coneixement experiencial", que pot ser d'especial

1. Professor del centre ERASME, Institut du Travail Social. 
interès per a la formació dels professionals, però també per als que participen en òrgans de presa de decisions. Entorn a aquesta qüestió, l'autor fa referència a propostes recents que posen en valor $\mathrm{i}$ incorporen el coneixement de les persones a qui s'adrecen les polítiques $\mathrm{i}$ les intervencions de l'àmbit social i sociosanitari.

Paraules clau: participació, coneixements experiencials, innovació, emancipació, política.

\begin{abstract}
Since 2002, the participation of people affected by the activities of the social and socio-sanitary field has been regulated in France in order to the assessment of the functioning of the institutions, activities and programs in these fields and in order to the elaboration of proposals. Since then, it has been food for thought and reflection to define, substantiate and promote it, and to adapt its development to the different areas and characteristics of the different agents that may be involved. The article identifies obstacles that make it difficult to participate in the institutional context in relation to the people affected, the professional teams and the institutions themselves, and it puts special attention to the way the issues of hierarchy and "power" can interfere with the development of participation proposals, even when what is supposedly intended is to foster the autonomy of the people being worked with. Finally, reference is made to innovative experiences and, in particular, those that value "experiential knowledge", which may be of special interest for the training of professionals, but also for those involved in decision-making bodies. In this regard, the author refers to recent proposals that value and incorporate the knowledge of the people to whom the policies and interventions in the social and socio-health field are addressed.
\end{abstract}

Key Words: participation, experiential knowledge, innovation, emancipation, politics. 
A França, la qüestió de la participació dels «usuaris» ocupa un lloc particular en els discursos i les pràctiques de la intervenció social. La llei del 2 de gener del 2002 per a l'actualització de les activitats socials $i$ sociosanitàries va inscriure aquest objectiu en els textos jurídics que emmarquen el treball social. Així, va permetre de crear mecanismes de participació de les persones afectades en la vida institucional: comissions de consulta, enquestes de satisfacció, grups d'expressió i, sobretot, Conseils de Vie Sociale (CVS), una eina de la democràcia representativa on es debaten les qüestions sobre el funcionament de la institució (activitats, propostes, acollida, organització interna, etc.). Més tard, la llei de l'11 de febrer del 2005 per a la igualtat de drets i oportunitats, la participació i la ciutadania de les persones amb discapacitat va recordar els principis de ciutadania i de participació en la vida social de les persones en situació de discapacitat. També es podria citar, entre altres signes d'un canvi de tendència a l'encalç de la participació de les persones afectades, la crítica del concepte d'usuari a favor del de persona afectada o acompanyada $^{2}$ o, fins i tot, en arribar la dècada dels 2000, la popularització del concepte d'“empoderament" amb la idea que ja no es tracta de fer "per", sinó de fer "amb".

Però què hi ha exactament darrere del concepte de participació? El 2017, l'Haut Conseil du Travail Social va proposar una definició que permet d'identificar els reptes quan s'abordi la qüestió de la seva aplicació en l'àmbit de la intervenció social:

"Participar és donar una opinió, manifestar l'experiència individual o collectiva i fer observacions i propostes. L'objectiu de la participació és millorar les condicions de vida i el funcionament de la nostra societat i les nostres institucions. Contribueix a la ciutadania, la integració i l'emancipació. És una eina de comunicació entre els professionals, els agents públics i les persones acompanyades”3.

És aquí on hom pot detectar diferències entre la idea i la realitat, entre la direcció fixada pels òrgans de presa de decisions i l'experiència de la vida institucional quotidiana. La qüestió de l'accés a la participació varia molt depenent de les institucions. L'escala

2. Informe del Conseil Supérieur du Travail Social, Merci de ne plus nous appeler usagers (2015): http://www.travail-social.com/Merci-de-ne-plus-nous-appeler

3.Extret de l'informe simplificat sobre la participació en els òrgans de govern i la formació dels treballadors socials de l'HCTS, 2017: https://solidarites-sante.gouv.fr/ministere/acteurs/instances-rattachees/haut-conseil-du-travail-social-hcts/rapports-et-publications-du-hcts/rapports/article/participation-des-personnes-accompagnees-aux-instances-de-gouvernance-et-a-la 
d'Arnstein ${ }^{4}$ és una eina que permet de mesurar els diferents graus de participació i la variabilitat observada, que es pot explicar sobretot per la vulnerabilitat del públic a qui s'acompanya. Així doncs, les formes i els objectius de la participació seran diferents entre, per exemple, un resident de les Maisons d'Accueil Spécialisé (MAS) amb múltiples discapacitats, limitat físicament i intel·lectualment, i un jove d'una Maison d'Enfants de caràcter social que busqui formació i habitatge. Paral-lelament a aquesta observació, es poden identificar una sèrie d'obstacles que dificulten la participació en el context institucional a diferents nivells:

1. A nivell de les persones afectades: autocensura, desconfiança i hostilitat envers els treballadors socials, efectes de la vergonya i la falta d'autoestima i confiança en un mateix, etc.

2. A nivell dels equips professionals: gestió de la urgència, pes de la rutina professional i inèrcia de la vida quotidiana; desconeixement del tema per falta de formació i informació; estereotips i prejudicis al voltant de l'accés a la participació; resistència, reconeguda o no, a la idea de concedir poder a les persones afectades («no és possible amb ells», «no ho aconseguiran»), etc.

3. A nivell de les institucions: efectes de la «clausura» envers el món de fora que limiten la introducció d'innovacions de l'exterior, herència de la cultura de «l'ajudantia» i de la relació de «finestreta», no-priorització de l'assumpte per part de les direccions, existència de Conseils de Vie Sociale «fantasmes» sense cap autoritat, etc.

La qüestió de la relació de poder retorna amb aquests bloquejos. Si considerem la participació com a una palanca d'emancipació (aquest és el cas, per exemple, del concepte d'empoderament ${ }^{5}$, basat en la idea d'atribuir poder d'actuació a aquells que no en tenen o ja no en tenen), és possible de distingir esculls relacionats directament amb el fet que hi ha «llocs» en una jerarquia institucional, una jerarquia que, a vegades, pretén amagar la seva existència darrere d'un vernís democràtic. Efectivament, pot semblar difícil que un treballador social delegui poder en les persones que acompanya, un poder que legitima no només un lloc, un estatus i

4.Aquesta escala, creada el 1969 per la sociòloga estatunidenca Sherry Arnstein (1971), té vuit graus de participació que comprenen des de la manipulació fins al control de la ciutadania.

5. També existeix una concepció neoliberal de l'empoderament, que es pot resumir amb l'expressió anglesa do it yourself o amb la francesa aide toi et Dieu t'aidera. 
un sou, sinó també un ordre social. El risc no reconegut de posar en perill la seva posició i la seva raó de ser a la institució a vegades pot explicar la reticència de certs professionals davant projectes de participació que es perceben com a massa «ambiciosos». Tanmateix, aquest rebuig a concedir poder s'oposa al projecte de suport a l'autonomia que sovint recorden els textos i els projectes institucionals. En aquest sentit, aquesta actitud s'uneix a la categoria de les comminacions paradoxals que poden perjudicar la qualitat del treball realitzat amb les persones.

Hi ha obstacles, però també iniciatives innovadores. La participació mitjançant la mobilització del coneixement experiencial de les persones afectades s'emmarca obertament en un enfocament emancipador, en línia amb la labor social política de persones com Saul Alinsky o Paolo Freire.

Cal recordar algunes coses sobre el concepte de coneixement: el camp del coneixement és, per definició, ampli. Comprèn coneixements teòrics, acadèmics, profans, tècnics, coneixements i habilitats vinculats a pràctiques (oficis, esports, etc.), però també coneixements relacionats amb situacions existencials: aquí s'inclouen els «coneixements d'allò que es viu» $\mathrm{O}$ «coneixements experiencials», directament extrets de la intimitat i l'experiència personal, que en un registre més prosaic s'anomenen «experiències vitals» $\mathrm{o}$ «escola de la vida».

Tanmateix, no n'hi ha prou amb ser pobres o viure en una cadira de rodes per saber què és la pobresa o la discapacitat. La confusió seria creure que el coneixement són sentiments subjectius o una recopilació d'anècdotes, mentre que, en realitat, es tracta de coneixements que s'obtenen a partir d'un treball de filtratge (mitjançant un exercici de reflexió, distància i comparació amb altres punts de vista) de les representacions i les experiències pròpies. Constituïts així, aquests coneixements són aprofitables per a la formació o es poden difondre en òrgans de presa de decisions, on poden adquirir el rang de perícia. A Bèlgica hi ha «experts d'allò que es viu» en matèria d'exclusió, pobresa o accés a l'assistència, experts que exerceixen d'interventors socials en els àmbits pertinents.

L'àmbit sanitari va tenir un paper rellevant en el reconeixement del coneixement experiencial amb l'aparició als anys 90 de la figura del "pacient-expert» ${ }^{6}$, alhora malalt i

6. La Universitat dels Pacients a França, creada el 2016, forma pacients perquè adquireixin coneixements especialitzats. Quan acaben, se'ls atorga un diploma: https://universitedespatients.org/ 
expert sanitari que pot ser cridat per intervenir en formacions mèdiques i paramèdiques. En l'àmbit social, ATD Quart Monde $e^{7}$ una associació important en la lluita contra la pobresa, va obrir el camí des de principis de la dècada dels 80 amb la lluita pel reconeixement del coneixement dels «pobres» sobre la seva situació. Actualment, «l'enfocament d'encreuament de coneixements i pràctiques» d'ATD Quart Món pretén crear un espai perquè el coneixement experiencial de les persones pobres pugui comparar-se i dialogar amb els coneixements científics i professionals. La trobada d'aquests tipus diferents de coneixements produeix un coneixement més precís i uns mètodes d'acció més en línia amb les preocupacions de les persones acompanyades. L'enfocament, que s'ha importat a molts països, està present en àmbits molt diversos: la salut, el treball social, l'educació, etc.

L’àmbit de la formació inicial en treball social també s'obre al coneixement experiencial de les persones afectades, també anomenades «persones recursos» ${ }^{8}$. A Tolosa, dues iniciatives al CRFMS-ERASME, una escola de treball social, illlustren la tendència: les conferències pedagògiques i la xarxa Power $U^{9}$.

Les conferències pedagògiques, organitzades un cop l'any i amb jornades al voltant d'una temàtica (el 2018 va ser la inclusió), es construeixen en col·laboració amb estudiants, persones recursos que participen en col-lectius i associacions, treballadors socials, formadors i investigadors. La jornada està formada per activitats, intervencions, pel-lícules o testimonis. Les persones recursos, a qui es remunera, estan presents al comitè d'organització, en garanteixen el marc amb els formadors i poden fer propostes.

Com la Universitat de Girona, el CRFMS-ERASME també és membre de Power Us, una xarxa d'escoles de treball social i centres universitaris creada el 2013 a Europa del Nord. Aquesta xarxa, mitjançant el principi de reparació de bretxes, que es pot resumir amb la idea de reduir les distàncies, tracta de reunir professionals i persones afectades tot promovent, entre altres coses, la intervenció de persones afectades en la formació dels

7.https://www.atd-quartmonde.fr/

8. La participation des personnes ressources concernées aux formations à l'intervention sociale, UNAFORIS, setembre del 2018: https://www.unaforis.eu/sites/default/files/public/fichiers/telechargements/2018_09_unaforis_guide_participation_personnes_ressources_concernees.pdf

9. https://powerus.eu. 
treballadors socials. Des del 2016, el CRFMS-ERASME recorre a persones recursos en situació de pobresa, discapacitat o exili perquè intervinguin en les diverses formacions que s'ofereixen.

El benefici de recórrer a persones afectades per a la formació és plural. Per als estudiants és una oportunitat per conèixer i relacionar-se amb «usuaris/àries» en un mateix espai i per tractar qüestions diferents de les que existeixen als seus llocs de pràctiques, amb la conseqüència que poden revisar les seves representacions sobre les vulnerabilitats i el lloc de persones singulars. Per a les persones afectades, la recompensa és evident en termes de reconeixement, autoestima i confiança en elles mateixes. També és la possibilitat de trencar l'aillament i el jo interior de les persones estigmatitzades perquè s'obrin a altres universos socials on és possible de formar noves aliances. Finalment, es tracta que prenguin consciència de la seva posició com a persones que poden reaccionar i actuar per fer front a les dificultats que presenta l'existència.

Els beneficis són reals per a tothom. No obstant això, per generar aquest cercle virtuós on tothom surt guanyador de la trobada amb l'altre, abans cal prendre una sèrie de precaucions. Adoptar el principi del voluntariat, crear un espai d'intercanvi amable, sense judicis, igualitari i basat en el respecte de tothom, i vigilar els desafiaments en matèria de poder i l'asimetria dels llocs són algunes de les solucions per resoldre la bretxa entre professionals i persones acompanyades.

\section{Bibliografia}

Arnstein, S. (1971). "A ladder of citizen participation". Journal of the American Planning Association, 35 (4), 216-224.

ATD Quart Monde [pàgina web: https://www.atd-quartmonde.fr]

Conseil Supérieur du Travail Social (2015). Refonder le rapport aux personnes. Merci de ne plus nous appeler usagers.

[recurs en línia: https://onpes.gouv.fr/IMG/pdf/Rapport_CSTS.pdf] 
Haut Conséil du Travail Social (2017). Participation des personnes accompagnées aux instances de gouvernance et à la formation des travailleurs sociaux. [pàgina web: https:// solidarites-sante.gouv.fr/ministere/acteurs/instances-rattachees/haut-conseil-dutravail-social-hcts/rapports-et-publications-du-hcts/rapports/article/participation-des-personnes-accompagnees-aux-instances-de-gouvernance-et-a-la]

Power Us. [pàgina web: https://powerus.eu]

Service Public Fédéral Intégration Sociale. Govern de Bèlgica (2020). Experts du vécu en matière de pauvreté et exclusion sociale [pàgina web: https://www.mi-is.be/fr/experts-du-vecu-en-matiere-dexclusion-sociale]

UNAFORIS (2018). La participation des personnes ressources concernées aux formations à l'intervention sociale. [recurs en línia: https://www.unaforis.eu/sites/default/files/ public/fichiers/telechargements/2018_09_unaforis_guide_participation_personnes_ressources_concernees.pdf] 
Xedagogia i Treball Social

Revista de Ciències Socials Aplicades

Edita: Universitat de Girona

Disseny i maquetació: info@clam.cat · 647427732

Dipòsit Legal: GI.904-2010

ISSN: 2013-9063 